\title{
El salvaje y la retórica colonial en El Orinoco ilustrado (1741) de José Gumilla S. J.
}

\author{
Carlos Del Cairo \\ Pontificia Universidad Javeriana, Colombia \\ cldelcairo@yahoo.com \\ Esteban Rozo Pabón \\ Pontificia Universidad Javeriana, Colombia
}

\begin{abstract}
Resumen
Este artículo constituye una aproximación hermenéutica a la obra El Orinoco ilustrado, escrita por el jesuita José Gumilla y publicada por primera vez en 1741. Los autores exploran los fundamentos de la retórica colonial que se advierte en el texto a través de la identificación de las instancias retóricas a las que recurre su autor para escribir la historia natural del Orinoco. Se resalta la funcionalidad geopolítica e imperial de las misiones en los territorios de frontera; la noción de historia en Gumilla; la diferencia colonial que se decreta a través de una retórica que recurre al cuerpo como instancia de manifestación del salvajismo, la ignorancia y el desgobierno de estas naciones, y la explicación teológica e histórica del origen y situación de los habitantes del Orinoco. Por último, se evidencian las representaciones y prácticas que justifican y hacen más eficaz el proyecto misional y civilizador, entre los "operarios" de la Compañía de Jesús en el siglo XVIII.
\end{abstract}

Palabras clave: GUMILLA, JESUITAS, MISIONES, DIFERENCIA Y RETÓRICA COLONIAL, RÍO ORINOCO, SALVAJISMO.

\begin{abstract}
This article develops a hermeneutical approach to the book El Orinoco ilustrado written by the Jesuit José Gumilla and published for the first time in 1741. The authors explore the main issues that underlie the colonial discourse in the text through the rhetoric figures built by Gumilla in order to write the Orinoco's natural history. In this sense, the article shows the geopolitical function of missionaries in border lands, the sense of history in Gumilla, the colonial difference expressed by factors such as the body as revelation of savagery, the ignorance and anarchy, and the historical and theological explanation of the origins of those peoples. Finally, the representations and practices between the "operarios" of the Company of Jesus in $18^{\text {th }}$ century are exposed.
\end{abstract}

Key words: GUMILLA, JESUITS, MISSIONS, COLONIAL DIFFERENCE, COLONIAL RHETORIC, ORINOCO RIVER, SAVAGERY. 


\section{Introducción}

Sin lugar a dudas El Orinoco ilustrado de José Gumilla, se ha convertido en un componente fundamental del corpus utilizado para reconstruir e interpretar la historia misional de los jesuitas en la América hispánica del siglo XVIII, conjuntamente con otros escritos como la Historia de las Misiones de los Llanos de Casanare y los ríos Orinoco y Meta, de Juan Rivero o La Historia de la Compañía de Jesús del Nuevo Reyno de Granada en la América de José de Cassiani ${ }^{1}$ ¿Cuál es, entonces, la pertinencia de proponer una lectura antropológica del texto de Gumilla? ¿El Orinoco ilustrado puede considerarse un documento susceptible de ser analizado como una fuente etnográfica? Siendo así, ¿cuáles son los supuestos que están detrás de la escritura, de las categorías y de las representaciones que Gumilla elabora en su obra? y ¿cómo pensar el proyecto civilizador y evangelizador de los jesuitas a partir de El Orinoco ilustrado?

Para responder a estos interrogantes la lectura que aquí se propone tiene como fundamento reconstituir la retórica colonial en el documento de Gumilla teniendo como eje la episteme y el locus de enunciación que condicionan el texto. La retórica colonial hace referencia a los discursos que producen al "otro" como

\footnotetext{
${ }^{1}$ Juan Rivero, Historia de las Misiones de los Llanos de Casanare y los ríos Orinoco y Meta (Bogotá: Silvestre, 1736) o José de Cassiani, La Historia de la Compañía de Jesús del Nuevo Reyno de Granada en la América (Madrid, España: Imprenta Manuel Fernández, 1741). Para una contextualización general de las misiones jesuitas en los Llanos Orientales y la Amazonia, se pueden consultar, entre otros, los trabajos de José del Rey Fajardo, Misiones jesuíticas en la Orinoquia (Caracas: Universidad Católica Andrés Bello, 1977); "La presencia científica de la Universidad Javeriana en la Orinoquia", Boletín de Historia y Antigüedades (Bogotá), 79, núm. 179 (1992): 925-952; "El mundo intelectual y simbólico del misionero orinoquense", en Un reino en la frontera. Las misiones jesuitas en la América colonial, coords. Sandra Negro y Manuel M. Marzal (Lima: Pontificia Universidad Católica del Perú; Abya-Yala, 2000); El aporte de la Javeriana colonial a la cartografia Orinoquense (Bogotá: Pontificia Universidad Javeriana, 2003); Jorge Enrique Salcedo, "Las misiones jesuitas en Colombia, las regiones del Casanare y el Meta durante el siglo XVII y XVIII", en Un reino en la frontera. Las misiones jesuitas en la América colonial, coords. Sandra Negro y Manuel M. Marzal (Lima: Pontificia Universidad Católica del Perú; Abya-Yala, 2000); David Sweet, 'Misioneros jesuitas e indios 'recalcitrantes' en la Amazonia colonial", en De palabra y obra en el Nuevo Mundo, eds. Miguel LeónPortilla y otros (Madrid: Siglo XXI, 1992), 265-292; Mary-Elizabeth Reeve, "Regional interaction in the western Amazon: The early colonial encounter and Jesuit years: 15381767”, Ethnohistory (Durham, Estados Unidos) 41, núm. 1 (1994): 106-138; Juan Manuel Pacheco, Los jesuitas en Colombia, t. 3 (1696-1767; Bogotá. Universidad Javeriana, 1989); Daniel Restrepo, La Compañia de Jesús en Colombia: compendio historial y galería de ilustres varones (Bogotá: Corazón de Jesús, 1940); y Eugene Parker, "Caboclization: The transformation of the amerindian in Amazonia 1615-1800", en Studies in Third World Societies (Williamsburg, Estados Unidos), 32 (1985): 1-49.
} 
salvaje en zonas de contacto donde existen unos que nombran y otros que son nombrados desde la episteme de aquellos. Esta retórica tendrá efectos prácticos en cuanto sirve como soporte ideológico y cultural de la dominación colonial. Ahora, por episteme entendemos los códigos que estructuran discursos, prácticas y sistemas perceptivos que modelan órdenes empíricos referidos a qué se ve y cómo se debe ver ${ }^{2}$. De otro lado, el locus de enunciación alude a las posiciones dadas por circunstancias concretas ideológicas, sociales y políticas desde las cuales se construye y se da sentido a lo real. Así, episteme y locus de enunciación harán posible la comprensión de la retórica colonial en esta obra de Gumilla.

En este orden de ideas, la reflexión propuesta constituye una hermenéutica de $E l$ Orinoco ilustrado, que se preocupa por identificar, principalmente, las instancias retóricas a las que recurre su autor, más que a la eventual correspondencia que guarda el documento con "la realidad" que busca describir. A partir de allí, se traza una serie de elementos que permiten discutir sobre: la funcionalidad geopolítica e imperial de las misiones en los territorios de frontera, la noción de historia en Gumilla, la diferencia colonial que se decreta a través de una retórica que recurre al cuerpo como instancia de manifestación del salvajismo, la ignorancia y el desgobierno de estas naciones, y la explicación teológica e histórica del origen y situación de los habitantes del Orinoco. Por último, se evidencian las representaciones y prácticas que justifican y hacen más eficaz el proyecto misional y civilizador, entre los “operarios" de la Compañía de Jesús en el siglo XVIII.

\section{Gumilla y su obra: contexto histórico}

El padre José Gumilla, S. J. (1686-1750) arribó al Nuevo Reino de Granada en 1705 , un año después de haber ingresado a la Compañía de Jesús en el noviciado de Sevilla, con la intención de hacer parte de "las misiones del Nuevo Mundo"3. Su formación jesuita tuvo lugar en la Universidad Javeriana de Bogotá y en 1714 recibió la ordenación sacerdotal luego de estudiar filosofía y teología. Según escriben los biógrafos e historiadores de la Compañía, en 1715 Gumilla fue escogido por el padre provincial Mateo Mimbela para ocuparse de la evangelización de los betoyes en el río Apure ${ }^{4}$ como respuesta a la petición de un cacique "jirara de nación" llamado Antonio Calaimi ${ }^{5}$. Hacia 1723 Gumilla fue

\footnotetext{
${ }^{2}$ Michel Foucault, Las palabras y las cosas. Una arqueología de las ciencias humanas (1966; México: Siglo XXI, 1998), 5.

${ }^{3}$ Pacheco, Los jesuitas, 468.

${ }^{4}$ Ibídem; Restrepo, La Compañia de Jesús.

${ }^{5}$ De acuerdo con Restrepo, la cristianización de los betoyes sucedió así: "Fue instrumento de la Providencia para atraer a los Betoyes un Cacique de grande ánimo e ingenio llamado Don Antonio Calaimi, de nación jirara; el cual, después de una peregrinación aventurera por el Nuevo Reino, y regresando a los confines de éste con Venezuela, oyó hablar en la ciudad de Pedraza a unos indios que tenían lengua semejante a la suya. Supo que eran de
} 
nombrado superior de las misiones de Orinoco, Meta y Casanare, evento que coincide con la creación de la misión del Meta ${ }^{6}$.

Después de quince años de difíciles estancias en los Llanos Orientales, Gumilla fue "destinado en 1731 por el P. Francisco Antonio González a restaurar con el P. Bernardo Rotella la difícil misión del río Orinoco, en la cual los indios caribes son una continua amenaza"7. Ese momento marcaría el inicio de su labor a lo largo del alto Orinoco, cuyos efectos sintetiza Arboleda en los siguientes términos: "fundó seis pueblos, estudió lenguas indígenas, y se dio a conocer como civilizador inteligente y sagaz, que intuyó lo que debían ser las 'doctrinas' del poderoso río"8.

Pocos años después, realizó un viaje a la Guayana para entrevistarse con las autoridades y pasó luego a la isla de Trinidad ${ }^{9}$. En 1734, de regreso en Guayana, firmó un convenio sobre los límites de las respectivas misiones con los capuchinos de la Guayana y los franciscanos de Píritu. En 1736 fue a Caracas para arreglar varios asuntos de la misión, en especial el de los "límites de la misión del Orinoco con la de los capuchinos de Caracas que no habían sido tenidos en cuenta en el anterior convenio de 1734"10. Hacia 1737, Gumilla asumió temporalmente el cargo de Rector del Colegio de Cartagena y en 1738 fue escogido como Procurador General de la Provincia ante la Corte Española y General de la Compañía de Jesús, junto con el P. Diego Terreros. Una vez en Madrid, en 1741 publicó la primera edición de El Orinoco ilustrado con el objetivo explícito de "dar a conocer" este territorio y, como escribió en su primer capítulo, para "que el gran río Orinoco, hasta ahora casi desconocido, renazca en este libro con el renombre de ilustrado, no por el lustre que de nuevo adquiere, sino por el caos del olvido, de que sale á la luz pública $^{11}$. En 1743 Gumilla regresó al Nuevo Reino con una expedición de

una tribu llamada de los Betoyes; y ganándoles la voluntad, se fue con ellos. Después de largas peripecias y gravísimo peligro de la vida (la que sólo por su sangre fría logró salvar), redujo a unos cuantos a que le siguieran a la Misión de Tame, a la que llegó con diez y seis Betoyes, base de la conversión copiosa que después se logró de ese pueblo". Restrepo, La Compañía de Jesús, 108.

${ }^{6}$ Rey Fajardo, Misiones jesuíticas, 126.

${ }^{7}$ Pacheco, Los jesuitas, 468.

8 José Rafael Arboleda, "El padre Gumilla S. J. y su obra", en El Orinoco ilustrado. Historia Natural, Civil y Geográfica de este gran río, José Gumilla (1791; Bogotá: ABC, 1955), 10.

${ }^{9}$ Pacheco, Los jesuitas, 468.

${ }^{10}$ Ibídem, 469.

11 José Gumilla, Historia Natural, Civil y Geográfica de las Naciones situadas en las riveras del Río Orinoco, 2 t. (1741; Barcelona: Carlos Gibert y Tutó, 1791), vi. Para la elaboración de este escrito trabajamos tres versiones del texto de Gumilla (1791, 1955 y 1994), sin embargo, la mayor parte de las citas textuales de El Orinoco ilustrado que aparecen aquí utilizan su grafía y estructura original, y son tomadas de la edición ampliada de 1791, que comprende dos tomos, corregida por el P. Ignacio Obregón y publicada en 
misioneros y siete años después murió en "su amada misión de Los Llanos"12, pero antes de su regreso dejó preparada una versión ampliada que sería publicada post mórtem en 1745.

La obra original de Gumilla comprende aprobaciones de autoridades eclesiásticas y civiles, un prólogo "para la inteligencia de la obra", una protesta del autor y dos partes que están organizadas siguiendo tópicos que inician con la descripción geográfica y natural de la región, pasando por la descripción de lo "genios, usos y costumbres" de las naciones del Orinoco y concluyendo con reflexiones sobre el sentido de la misión y los valores de los operarios. La primera parte contiene una introducción y veinticinco capítulos, mientras que la segunda comprende una introducción y veintisiete capítulos. Cada capítulo sigue un modelo de argumentación que el mismo Gumilla define así: "en las primeras cláusulas de cada addicion se verá propuesta la duda y el modo de dudar; y en el contexto se hallará la respuesta pretendida, coroborada y autorizada" ${ }^{\prime 13}$. Es decir, el autor inicia cada capítulo planteando interrogantes sobre materias específicas que se encargará de resolver a partir de los temas y ejemplos que le proveen el Orinoco y sus naciones.

\section{La misión: institución imperial en territorios de frontera}

Debido a que el locus de enunciación de Gumilla está marcado, entre otras cosas, por su condición de jesuita misionero, es preciso partir de unas consideraciones generales sobre los sentidos y funciones de las misiones. A este respecto, resulta pertinente puntualizar que el modelo colonizador de la población indígena implementado desde la Conquista y basado en el sometimiento y sujeción física, a través de la violencia y la esclavización, venía siendo cuestionado por algunos humanistas desde el siglo XVI. Lo anterior trajo como consecuencia la búsqueda de modelos colonizadores alternos que pusieran su énfasis en el adoctrinamiento moral más que en la sujeción y coacción física, por lo cual, en el siglo XVIII, las misiones se constituyen en el modelo civilizatorio más complejo y metódico en virtud, con el que intentará promover los valores cristianos y el deber con la Corona a través de la persuasión y el convencimiento de los gentiles ${ }^{14}$. Lo anterior no significa que el adoctrinamiento moral y espiritual estuviese ausente en los primeros siglos de dominio español; por el contrario, y de acuerdo con Barona ${ }^{15}$,

Barcelona en la imprenta de Carlos Gibert y Tutó. A menos que se indique lo contrario, las citas corresponden al primer tomo.

12 Pacheco, Los jesuitas, 472.

${ }^{13}$ Gumilla, Historia Natural, 6.

${ }^{14}$ Michèle Duchet, Antropología e historia en el siglo de las Luces (México: Siglo XXI, 1975).

${ }^{15}$ Guido Barona, "Las tecnologías de dominación colonial: el derecho, los pueblos de indios y resguardos", Revista de Antropología y Arqueología (Bogotá), 10, núm. 2 (1998): 93-140. 
desde los albores mismos de la Conquista se implementaron ciertas "tecnologías de dominación colonial", como el requerimiento o el resguardo, que sirvieron para garantizar de palabra y, de facto, la proyección del "ethos civilizador" en las tierras conquistadas, respaldadas por un sistema jurídico fundamentado en los presupuestos filosóficos e ideológicos promovidos principalmente por Francisco de Vitoria ${ }^{16}$.

De acuerdo con sus efectos pragmáticos, las misiones requieren ser pensadas como complejos dispositivos donde se lleva a cabo, en primera instancia, la nucleación poblacional para hacer posible la evangelización y civilización de gentiles, pero que sirven simultáneamente a intereses geopolíticos imperiales. Como bien lo expresó Del Rey: "La cristianización se concibe como un proceso que se inicia con la 'reducción', continúa con la educación e incorporación a la vida civil, y concluye con la conversión"17. Siguiendo a Rausch, podríamos afirmar que "la misión fue la institución imperial más importante en la época de la Colonia"18, en la medida que la eficacia y funcionalidad de la nucleación y evangelización que ejerció sobre las poblaciones locales bajo su tutela trascendieron al ámbito geopolítico $^{19}$. Por consiguiente, el esfuerzo de los jesuitas por cartografiar y administrar regiones periféricas convirtió a las misiones en herramientas fundamentales para la negociación y delimitación de fronteras entre los imperios ${ }^{20}$. Como agentes encargados de facto de las gentes y territorios de los Llanos Orientales, las misiones constituyeron complejas estructuras que actuaron como articuladoras de estas latitudes a la dinámica del interior y, simultáneamente, obstaculizaron las apetencias extranjeras, particularmente lusitanas, aunque también francesas, inglesas y holandesas cuyos funsionarios usaron el corredor entre la Guayana y la región del alto Orinoco-río Negro para explorar nuevos territorios y captar mano de obra esclava. Por tales razones, las misiones emergen

\footnotetext{
${ }^{16}$ Ibídem.

${ }_{18}^{17}$ Rey Fajardo, Misiones jesuíticas, 168.

18 Jane Rausch, Una frontera de la sabana tropical. Los Llanos de Colombia 1531-1831 (Santafé de Bogotá: Banco de la República, 1994), 415.

${ }^{19}$ Ese ámbito geopolítico refiere a la articulación de la esfera geográfica y política por la cual se trazan dispositivos de poder en el espacio. En efecto, "la geografía fue una ciencia cultivada con pasión por los jesuitas del Barroco"; tanto así que "el cargo de Cartógrafo Mayor de Indias siempre residió en un miembro de la Compañía de Jesús". Rey Fajardo, El aporte de la Javeriana, 15, 17.

${ }^{20}$ En el caso que nos ocupa, las disputas entre los imperios español y portugués arreciaron después de la independencia de Portugal de la Corona española en 1668, y no cesaron hasta que se firmó el Tratado Preliminar de Límites de 1777. Eric Beerman, "Retrato biográfico de Francisco Requena (1743-1824)", Boletín de Historia y Antigüedades (Bogotá), 85, núm. 801 (1998): 502.
} 
como enclaves eficaces para los procesos civilizatorios y posibilitan el ejercicio imperial de la Corona española sobre las tierras de oriente ${ }^{21}$.

En el escenario concreto de la Orinoquia, los jesuitas establecieron misiones que reflejan el modelo misional integral, según el cual la conversión de gentiles pasaba tanto por el adoctrinamiento como por el adiestramiento en artes $\mathrm{y}$ oficios particulares que promovían la disciplina, laboriosidad y entrega en los gentiles, concebidos como proclives a la pereza y a la satisfacción de los deseos terrenales. En algunos casos, estas misiones jesuitas dieron lugar a grandes haciendas dedicadas al mantenimiento y reproducción de ganado vacuno así como a ciertas labores agrícolas de menor envergadura; además, tuvieron un éxito económico ponderado en virtud de la adecuada adaptación del ganado a las condiciones climáticas regionales. No obstante, resulta imposible afirmar que la experiencia ganadera de los jesuitas se inicia en los Llanos Orientales; la evidencia indica que "desde el siglo XVII la experiencia de los jesuitas en el manejo de haciendas en Hispanoamérica estaba consolidada" 22 .

De esta manera, se marca una diferencia fundamental entre las estrategias del proyecto civilizatorio desplegadas en el contexto neogranadino andino y en las tierras bajas de oriente: en el primer caso, la colonización se articula principalmente a través de la encomienda y las reducciones misionales mientras que en el segundo se efectúa a partir de las misiones y la hacienda, esta última en el caso particular de las misiones jesuitas.

\section{La historia según Gumilla: moral e Ilustración}

Como bien se puede apreciar en uno de los múltiples significados que evoca el título, El Orinoco ilustrado no escapó al momento cultural que se vivía en Europa. Según el jesuita Pacheco: "la Ilustración se había difundido con su entusiasmo y curiosidad científica, y eran bien recibidos los libros de viajes y de países extraños" ${ }^{\prime 2}$. El carácter ilustrado y enciclopédico del texto se hace más evidente en el subtítulo: Historia natural, civil, y geographica, de este gran rio, y de sus caudalosas vertientes: govierno, usos, y costumbres de los indios sus habitadores, con nueva, y utiles noticias de animales, arboles, frutos, aceytes, recinas, yervas, y

21 Carl Langebaek y otros, Por los caminos del Piedemonte. Una historia de las comunicaciones entre los Andes orientales y los Llanos. Siglos XVI a XIX, Estudios Antropológicos, núm. 2 (Santafé de Bogotá: Universidad de los Andes, 2000); Rausch, Una frontera.

${ }^{22}$ Augusto Gómez, Indios, colonos y conflictos. Una historia regional de los Llanos Orientales. 1870-1970 (Bogotá: Pontificia Universidad Javeriana; Instituto Colombiano de Antropología; Siglo XXI, 1991), 40.

${ }^{23}$ Pacheco, Los jesuitas, 474. 
raices medicinales: $y$ sobre todo, se hallaran conversiones muy singulares de nuestra santa fe, y casos de mucha edificacion.

De esta manera, para entender la escritura producida desde el locus de enunciación de Gumilla, es necesario aproximarse a la noción de historia que subyace al texto. En El Orinoco ilustrado se identifica una oscilación del sentido medieval de la historia, que va desde un discurso moral, que apunta a mostrar los vicios y virtudes del tema en cuestión, como lo desarrolla Borja para el caso de la Conquista, hasta un discurso ilustrado que enfatiza en la verdad de las descripciones garantizada por la experiencia de aquel que escribe ${ }^{24}$. En el primer extremo, la retórica de Gumilla se soporta en una tradición escolástica y cristiana que tiene su fundamento en el modelo de la autoridad. Este modelo parte de verdades apodícticas decretadas por autores cristianos y antiguos; en el otro extremo, se identifica una versión ilustrada de la historia que tiene por objeto persuadir al lector de la verdad apelando a una descripción "fiel y transparente" que busca eliminar del argumento cualquier posibilidad de magnificación o denigración: "apuntaré lo que ocurriere, y lo que ofreciere el contexto de la Historia: apartaré como tierra inútil, lo que hallare no ser conforme con la realidad de lo que tengo visto y experimentado" ${ }^{\text {"25 }}$.

¿La fluctuación del sentido de la historia que emerge de la obra de Gumilla, constituye una contradicción? Argumentamos que no, en virtud de la doble condición que lo embarga como sujeto histórico: un jesuita en los albores de la Ilustración, para quien esta no le es indiferente. De allí que su discurso oscile entre una descripción de las gentes y lugares del Orinoco "tal y como son" y su incorporación en la cosmovisión judeo-cristiana. Estas circunstancias hacen de $E l$ Orinoco ilustrado una obra de corte ilustrado y enciclopédico que abarca "países, naciones, animales y plantas incógnitas" que serán documentados con "claridad y método" $\mathrm{y}$, en este sentido, también busca describir lo natural, civil y geográfico del río apelando a la autoridad que le confiere el haber estado allí, donde la observación y la experiencia se constituyen en signos de la verdad del texto. De hecho, los documentos que refrendan la publicación de la obra, incluidos en la primera edición, coinciden en señalar su veracidad acudiendo al argumento de la experiencia, como bien lo señala el maestro Antonio de Goyeneche, del Colegio Imperial de la Compañía de Jesús, al referirse a las virtudes del texto de Gumilla:

Suele la cortedad del humano entendimiento, hacer transito de lo admirable a lo increíble, para hacer luego lo increíble fabuloso. Para precaver este

\footnotetext{
${ }^{24}$ Jaime H. Borja G, Los indios medievales de Fray Pedro de Aguado. Construcción del idólatra y escritura de la historia en una crónica del siglo XVI (Bogotá: Pontifica Universidad Javeriana; Icanh; Instituto Pensar; Universidad Iberoamericana de México, 2002).

${ }^{25}$ Gumilla, Historia Natural, iv.
} 
engaño el autor, autoriza la verdad con la circunstancia de haber sido testigo de cuanto escribe, sino es de uno, $\mathrm{u}$ otro suceso que debió a informe de persona muy justificada, como él mismo lo advierte, con aquella ingenuidad, que no es la menor de sus religiosas prendas ${ }^{26}$.

Al mismo tiempo, para Gumilla la historia tiene una función moral ineludible que se desprende de su fin primario: "disipar" las dudas y poner en orden el archivo. Según lo expresa el misionero en la introducción a la primera parte del texto:

La historia, no sólo es abonado testigo de los tiempos; es, y debe ser también luz para todas las edades y generaciones. Y al modo, que si falta la luz, en las más curiosa galería, todo aquel archivo de las más apreciable antigüedad, pasa a un caos de confusión, pareciendo ordinarias las piedras más selectas, y borrón tosco la más sutil miñatura: no de otra manera, la más curiosa historia, si le faltare la luz, claridad, distinción, y método, será toda confusión, y origen de muchas dudas, contra el fin primario de la historia, que tira a disiparlas ${ }^{27}$.

Precisamente, en el comentario que hace Dionisio de Alcedo y Herrera ${ }^{28}$ al texto de Gumilla se puede apreciar la fluctuación de criterios en la escritura de El Orinoco ilustrado. En su dictamen, el funcionario de la Corona escribe:

[...] la empecé a leer con cuidado, la proseguí con deleite, y la acabé con admiración, por la felicidad con que V. R. logra desempeñar en ella los tres preceptos de la historia, en la energía del estilo, en la pureza de la verdad, y en la claridad del orden, sacando de estos dos libros aquellos cinco utilísimos efectos, que quería el gran maestro de la elocuencia Cicerón, en los tres que dedicaba a Léntulo, y escribió de los sucesos de su consulado: Tesis temporum, lux veritatis, vita memoriae, magistra vitae, et nuntia vetustatis ${ }^{29}$.

Así, testigo de los tiempos, luz de la verdad, vida de la memoria, maestra de la vida y anunció de lo que pasó, son las cinco características que De Alcedo y Herrera

${ }^{26}$ Antonio de Goyeneche, "Aprobación del R. P. Maestro Antonio de Goyeneche, de la Compañía de Jesús”, en El Orinoco ilustrado. Historia Natural, Civil y Geográfica de este gran rio, José Gumilla (1741; Bogotá: ABC, 1955), 24.

${ }_{27}^{27}$ Gumilla, El Orinoco ilustrado, 1: 47.

28 Este dictamen fue realizado por el gobernador general de la Provincia de Quito y posterior presidente de las reales audiencias de Quito y de Panamá en el año de 1741.

${ }^{29}$ Dionisio de Alcedo y Herrera, "Dictamen de D. Dionisio de Alcedo y Herrera, Gobernador y Capitán General que fue de la Provincia de Quito, y Presidente de la Real Audiencia de dicha ciudad, en orden al contenido de esta historia”, en Gumilla, El Orinoco ilustrado, 1: 32 . 
elogia en El Orinoco ilustrado. Para este funcionario el texto es un fiel reflejo de "lo que es aquel gran río", escrito por un "testigo de vista". Para el comentarista, la única inclinación que se expresa en el texto responde a la pasión por "la conversión de aquella gentilidad, cuyos requisitos califican relevantemente, con indefectible certidumbre, la indubitable seguridad de la verdad" ${ }^{30}$.

Por último, la obra de Gumilla se une al esfuerzo de otros jesuitas que con sus libros e historias estudiaban "lo Natural, Civil y Geográfico de sus respectivas Misiones," y así "nos dexáron de paso mucha enseñanza y mucha luz" ${ }^{31}$. Gumilla sólo aspira a realizar algunas reflexiones, que "den luz y prevengan los ánimos de los Operarios que Dios nuestro Señor llamare al cultivo espiritual de aquella mies $^{32}$.

\section{Diferencia colonial en El Orinoco ilustrado}

La diferencia colonial refiere al encuentro tanto físico como imaginario entre distintos horizontes culturales ${ }^{33}, \mathrm{y}$ ese encuentro tiene un carácter asimétrico y dicotómico donde unos nombran con cierta autoridad y otros son nombrados por ellos, produciendo estereotipos de la alteridad y construcción de la identidad a través de oposiciones binarias: civilizado/salvaje, culto/inculto, cristiano/gentil, humano/bestia o moral/inmoral que llevan a una diferencia taxativa de fondo: Occidente/no Occidente. Podríamos decir que la relación entre diferencia colonial y situación colonial es dialéctica, porque los aspectos políticos e ideológicos se legitiman mutuamente.

El Orinoco ilustrado parte de una premisa fundamental: lo que hay en el Orinoco, y en general en el Nuevo Mundo, es nuevo para Europa más por su diferencia radical que por su "reciente" descubrimiento:

\footnotetext{
${ }^{30}$ Ibídem, 34.

${ }^{31}$ Gumilla, Historia Natural, iv.

${ }^{32}$ Ibídem.

${ }^{33}$ De una manera más compleja, y de acuerdo con Mignolo, la diferencia colonial refiere a: “el espacio donde se 'activa' la colonialidad del poder. Es también el espacio donde se está llevando a cabo la restitución del conocimiento subalterno y donde está emergiendo el 'pensamiento de frontera' (border thinking). La diferencia colonial es el espacio donde las historias locales que están inventando e implementando diseños globales encuentran (otras) historias locales, es el espacio en el cual los diseños globales tienen que ser adaptados, adoptados, rechazados, integrados o ignorados. Finalmente, la diferencia colonial es la 'locación' tanto física como imaginaria donde la colonialidad del poder entra en funcionamiento en su confrontación con dos tipos de historias locales dispuestas en tiempos y espacios diferentes a través del planeta”. Walter Mignolo, Local histories/global designs. Coloniality, subaltern knowledge and border thinking (Princeton: Princeton University Press, 2000), viii.
} 
[...] que vista con claridad la exîstencia innegable del Nuevo Mundo Americano, vean que siendo nuevo aquel todo, han de ser tambien nuevas las partes de que se compone; porque no solo se llama Mundo Nuevo, por su nuevo descubrimiento; sino también porque comparado con este Mundo antiguo, aquel es del todo nuevo, y en todo diverso ${ }^{34}$.

Este carácter "único" y específico del Nuevo Mundo termina constituyendo el marco ontológico de la diferencia colonial, es decir, de la colisión de historias locales en un escenario de colonización, al tiempo que sirve de fundamento a la "novedad" y "peculiaridad" de los habitantes de estas regiones. Novedad que radica, básicamente, en sus hábitos morales: ignorancia, ingratitud, inconstancia, pereza, miedo e inclinación a las bebidas embriagantes, son los principales obstáculos que enfrentan los misioneros en sus labores de conversión de los gentiles. En palabras de Gumilla:

A vista pues de tantas cosas nuevas, es preciso que no cause novedad el que los hombres, que la Divina Providencia destinó para que disfruten tierras, mares, rios, bosques, prados, y selvas nuevas, parezcan tambien hombres nuevos, y nos causen tanta menor novedad, quanto ménos se reconoce en ellos de racional ${ }^{35}$.

En efecto, el caso de El Orinoco ilustrado demuestra un elemento sustancial en la elaboración literaria de los sujetos y colectivos representados a través de la retórica colonial: la forma de naturalización y gradación de la alteridad de acuerdo con los valores que representa cada una de las naciones que describe. Como podremos ver, los misioneros españoles desarrollaron criterios específicos para juzgar, clasificar y jerarquizar las sociedades humanas bajo un esquema temporal y espacial que se estructura en torno al eje barbarie-civilización y, a partir, de una de serie de signos y "costumbres" que configuran la idea del gentil-salvaje.

Estas construcciones, obviamente, son elaboradas desde un locus de enunciación específico: el proyecto civilizatorio ilustrado que se sustenta en la superioridad moral de la "civilización cristiana europea". Uno de los pilares de este proyecto será la producción retórica de la alteridad a través de crónicas, relatos de viaje y escritos de diversa índole que decretan la diferencia; en otras palabras, definen quién es el otro, cómo es, de dónde viene y qué se puede hacer con él. De ahí que a la pregunta: “¿Qué hombres se halláron, y cada dia nuevamente es (sic) descubren en las Américas?" Gumilla responda: "hombres sin Dios, sin ley, sin cultivo,

\footnotetext{
${ }^{34}$ Gumilla, Historia Natural, viii.

${ }^{35}$ Ibídem, xi.
} 
toscos, agrestes, con un bosquejo craso de racionalidad"36 que pueden ser cultivados a través de su evangelización.

El Orinoco ilustrado da cuenta de las formas como se produce e interpreta la diferencia cultural desde las reglas y cánones que el "colonizador" utiliza para describir al otro. En efecto, la estrategia a la que acude Gumilla consiste en descubrir (iluminar) a los gentiles a través de categorías descriptivas que empiezan a ser recurrentes en los cánones ilustrados y católicos: las referencias a la geografía, las Sagradas Escrituras, genealogías judeo-cristianas, taxonomías vegetales y animales, la historia, la anatomía, entre otras, como instancias que ponen en contexto el conocimiento adecuado del otro con un trasfondo latente de veracidad.

De tal manera, esa intencionalidad del discurso sobre la alteridad que se filtra en el texto de Gumilla marca su teleología: construir al otro para hacerlo susceptible de comprensión y, desde allí, legitimar el deber evangelizador de las misiones y la relevancia del proyecto civilizatorio. Se parte claramente de la necesidad de (d)escribir la historia de esas naciones para decretar su veracidad y, consecuentemente, legitimar el deber-función evangelizador del misionero. Emerge así una retórica que resalta la ambigüedad moral de estos gentiles y su gradación interna -que evoca a unas naciones más y otras menos salvajes-, a través de la enunciación de sus vicios, degeneración e idolatrismo que solo pueden ser revertidos al acoger la buena nueva del Señor.

La naturalización del "otro" se da con la producción de estereotipos que recurren a una instancia axiológica muy particular: el otro no solo carece de valores, sino que sus costumbres representan los antivalores ${ }^{37}$ del sujeto cristiano e ilustrado: son irracionales, salvajes y entregados a los vicios y placeres terrenales. Esa instancia de representación del otro acude al paradigma de la distancia. En efecto, la triple distancia geográfica, temporal y cultural traza un abismo insalvable -por sí mismo- entre aquel y el misionero, que solamente puede ser revertido por la vía del bautismo y la cristianización.

La distancia geográfica traza una equivalencia entre la lejanía y la inferioridad moral: "[...] quanto mas adentro penetran los Misioneros Apostólicos, tanto mayor es la maleza y barbaridad con que hallan preocupadas las Naciones"38. A su vez, esta distancia enmarca una segunda: la cultural. Cuando el imperio se expande y acoge en sus dominios esos territorios periféricos y gentes distantes, sus

\footnotetext{
${ }^{36}$ Ibídem, $\mathrm{x}$.

${ }^{37}$ Frantz Fanon, Los condenados de la tierra (1961; reimpresión, Santafé de Bogotá: Fondo de Cultura Económica, 1999).

${ }^{38}$ Gumilla, Historia Natural, 68.
} 
representantes (misioneros, militares, visitadores o encomenderos) se distancian culturalmente de aquellos con los que establecen relaciones de convivencia en estas regiones. Por lo tanto, y a pesar de articularlos en términos de la funcionalidad espacial, se requiere de un trabajo más denso para superar la distancia cultural determinada por la diferencia colonial: descivilizarlos para recivilizarlos en la lógica cristiana, y concretar así el proyecto universal de la Congregatio Fidelium ${ }^{39}$. Desde allí se marca la tercera distancia: el otro aparece como un estadio anterior, como un vestigio del pasado en el presente. A este respecto, resulta pertinente recordar que para Gumilla los indios americanos han pasado por "tres estados muy diversos entre sí":

En el primero veamos cómo estaban ántes que en el Perú ni en México dominasen los Ingas ni los Montezumas: ¡qué horror! cierranse de suyo los ojos, por no ver tan fea barbaridad. En el segundo estado registremos los dilatados Paises del Perú y de México, sujetos en gran parte, unos á los Ingas, otros á los Montezumas; rayando ya la disciplina Militar, y entablada á su modo la vida Civil en las Provincias y Naciones agrestes, que iban sujetando aquellos dos Emperadores. El tercer estado, feliz para tantos millones de Indios, como ya por la Bondad de Dios se han salvado y salvan (aunque infeliz para los que aun están en su ciega ignorancia, ó ciegamente resisten a la luz Evangélica) empezó desde que las Armas Católicas tomáron posesion de las principales Provincias de aquellos dos vastos Imperios; y prosigue hasta ahora, creciendo siempre en todos aquellos remotos ángulos del nuevo Mundo la luz de la Santa Fe, para eterna dicha de aquellos infelices hijos de Adán ${ }^{40}$.

Precisamente, los habitantes del Orinoco son un reflejo de ese:

Primer estado de aquellas gentes [que] hace á mi ver un confuso éco con las tinieblas, en que estaba envuelto el Mundo en aquellos tiempos antecedentes á la dignacion inefable, con que Dios se manifestó al Patriarca Abrahán, tiempos de barbaridad y de error ${ }^{41}$.

Por lo tanto, las distancias geográfica, cultural y temporal enmarcan al otro en un paradigma de la alteridad que solo es reversible al incluirlo, de facto, en el modelo cristiano-eurocéntrico, para lo cual es imprescindible "traducirlo" a través de la retórica colonial, con miras a decretar la verdad que hace del otro un ser distinto. Así, la superación de esas distancias es posible únicamente por el bautismo, y este,

\footnotetext{
${ }^{39}$ Guido Barona, "Memoria y olvido: pasión, muerte y renovación de la colonización del imaginario", en Memorias hegemónicas, memorias disidentes. El pasado como política de la historia, ed. Marta Zambrano y Cristóbal Gnecco (Bogotá: Ministerio de Cultura; Instituto Colombiano de Antropología e Historia; Universidad del Cauca, 2000), 121-150.

${ }^{40}$ Gumilla, Historia Natural, 66.

${ }^{41}$ Ibídem, 67.
} 
a su vez, es viable por una condición de base: por lejano y diferente que se represente al otro, este posee todas las potencialidades para ser incorporado en el mundo cristiano en cuanto comparte con el misionero el ser una criatura de Dios. En consecuencia, la tosquedad de esas gentes solo puede ser afinada "a fuerza de tiempo, paciencia y doctrina"42. Para evidenciar la retórica que marca y produce la diferencia colonial en El Orinoco ilustrado, se hará referencia a tres instancias que muestran claramente esas estrategias retóricas, que por un lado, determinan la dicotomía misionero/gentil y, por otro lado, legitiman el proyecto evangelizador. Estas instancias son: primero, el cuerpo como concreción del salvajismo; segundo, la ignorancia y el desgobierno; y, tercero, la explicación del origen de las naciones del Orinoco.

\section{El cuerpo: instancia de representación y naturalización de la alteridad}

Siguiendo el principio ilustrado que hace del cuerpo una metáfora de la condición moral de los sujetos, Gumilla plantea que antes de centrar la atención en la capacidad, propiedades, inclinaciones, usos de los indios americanos, es necesario fijar la vista en el "frontispicio y fachada" de aquello que se va a describir, pues la fachada termina siendo un "índice" de la arquitectura interior. Así, Gumilla argumenta que la "fisiognomía del rostro" de los indígenas, "contrapuesta con la de los Europeos, Africanos, Chinos y Tártaros, hace coro a parte, aunque sin disonancia" ${ }^{43}$. Aquello que verdaderamente disuena y hace de esa "fisiognomía extraordinaria de rostro" algo estéticamente feo y desagradable es el esfuerzo de los gentiles por "afearse notablemente con diaria untura de varios colores", de allí que "el que jamás los ha visto, á la primera vista se aturde, pensando que se le aparece una tropa de diablos en figura y apariencia de hombres" ${ }^{44}$. Gumilla traza una interesante analogía entre el carácter del indio y la funcionalidad moral de su cuerpo:

El Indio en general (hablo de los que habitan las selvas y de los que empiezan á domesticarse) es ciertamente hombre; pero su falta de cultivo le ha desfigurado tanto lo racional que en el sentido moral me atrevo á decir: "Que el Indio bárbaro y silvestre es un monstruo nunca visto, que tiene cabeza de ignorancia, corazón de ingratitud, pecho de inconstancia, espaldas de pereza, piés de miedo, su vientre para beber y su inclnacion (sic) á embriagarse: son dos abismos $\sin \mathrm{fin}^{45}$.

\footnotetext{
${ }^{42}$ Ibídem, 103.

${ }^{43}$ Ibídem, 70-71.

${ }^{44}$ Ibídem, 72.

${ }^{45}$ Ibídem, 103.
} 
La posibilidad de pensar la moral del otro desde su cuerpo remite a la naturalización de los (anti)valores que aparecen asociados a las distintas partes de ese "cuerpo distinto" (monstruoso), como se desprende del fragmento citado. La proclividad de los gentiles a asumir conductas que desde el locus cristianoeurocéntrico se conciben como antinatura, como el infanticidio, la promiscuidad, la desnudez o el canibalismo, entre otras, es el dramático resultado de la influencia demoníaca. En lugar de las deformaciones imaginadas desde el mundo antiguo como cíclopes, ménades, tritones, centauros o sátiros que recrearon al homo sylvestris en el Nuevo Mundo ${ }^{46}$, para Gumilla la monstruosidad de los gentiles la constituyen sus valores, no su cuerpo; este es simplemente un vehículo donde se materializan sus extrañas costumbres. La desnudez, el infanticidio, o la promiscuidad, entre otros antivalores destacados reiteradamente por Gumilla, tienen precisamente al cuerpo del otro como escenario de cristalización. Otro ejemplo de esta construcción retórica sobre el cuerpo es señalado por el autor en relación con el amamantamiento:

Bien pueden avergonzarse todas aquellas Señoras, que no por falta de amor, sino por no sé qué, se desdeñan de alimentar á sus pechos aquellas misma prendas, tan hijas de su corazon, á quienes despues de Dios, han dado el sér que tienen; y despues con notoria inconseqüencia niegan el pecho, negándoles el segundo sér [...] de que toma notable tintura y colorido el genio é inclinaciones de toda la vida, segun la opinion mas segura de los mejores Físicos. Este reparo, muy digno de hacerse, urge mucho mas á las señoras Americanas, en donde de su materno regazo arrojan á sus inocentes párvulos al seno de una Negra, de una Mulata ó de una India: ¿qué sangre ha de criar tal leche? y ¿qué inclinaciones? ¿y qué baxeza de ánimos? ${ }^{47}$.

En este pasaje, Gumilla incursiona en lo que podríamos concebir como una hermenéutica del cuerpo, donde, entre otras cosas, se atribuye a la leche materna la transmisión del carácter, por lo cual hay que regular la práctica de la maternidad sustituta, particularmente en el caso de las señoras americanas. En este planteamiento se reconoce la naturalización del comportamiento de estas gentes; es decir, en la medida en que los progenitores sean idólatras su proclividad a las malas maneras será transmitida a sus hijos. Solo cuando unos y otros sean convertidos se superará tan infame condición.

\section{La ignorancia y el desgobierno de los salvajes}

\footnotetext{
${ }^{46}$ Roger Bartra, El salvaje en el espejo (Barcelona: Destino, 1996).

${ }^{47}$ Gumilla, Historia Natural, 164-165.
} 
Si bien la producción de la alteridad en la diferencia colonial tiene un fuerte referente en la elaboración retórica del cuerpo indígena, resulta pertinente aclarar que para Gumilla la "barbaridad" de esos hombres que parecen fieras, no puede atribuirse exclusivamente a su "naturaleza"; más bien su carácter salvaje es "fruto necesario, y maleza, hija de una total falta de cultivo"48. De esta manera, la "barbaridad" de los gentiles aparece como resultado de sus hábitos, costumbres e inclinaciones. Entre las costumbres que Gumilla menciona sobresalen la desnudez y su "desgobierno civil y doméstico", la nula educación que dan a sus hijos, la poligamia, el canibalismo, el consumo de alucinógenos (Yupa) y el carácter belicoso de algunas naciones. Haciendo referencia a la desnudez de los indígenas, Gumilla plantea que esta responde no tanto a la inocencia, ausente en ellos, sino a la ignorancia que tienen de estar desnudos: "[...] no les causa rubor su desnudéz total; porque ó no ha llegado á su noticia que están desnudos, ó porque están desnudos de todo rubor ó empacho"49.

En síntesis, Gumilla argumenta que si bien los indígenas tienen noción de la vergüenza y el rubor, "la significación de las voces" está invertida, porque "al vestirse sienten rubor, se corren, y están sosegadas y contentas con su acostumbrada desnudez",50. El jesuita enfatiza que para ellos "estar untados", equivale a "estar bien vestidos": "para ir á la guerra los adultos, se pintan fea y horriblemente" $"$. Corresponde, entonces, a los misioneros hacerlos caer en cuenta de su desnudez, es decir, enseñarles los hábitos y las morales que configuran al cuerpo cristiano para liberarlos de su ignorancia.

Por otra parte, Gumilla es enfático en demostrar que los indígenas carecen de cualquier forma de orden social; es más, viven en completo "desgobierno" que constituye la causa de su barbarie. Si "el gobierno civil de las leyes que los reinos y repúblicas se imponen" busca alcanzar su "union, paz, conservación y aumento", nada de esto, dice Gumilla, "ni aun sombra de ello he notado en las Naciones de que trato, ni en general, ni en alguna en particular" ${ }^{\prime 2}$. Inclusive, parecería que: "qualquier hormiguero de los que en aquellos territorios he observado, [...] se gobierna con mejor regularidad y régimen, que cada una de las muchas Naciones que he tratado" ${ }^{33}$.

Esto da como resultado, en lo que respecta a su "gobierno en general o desgobierno, propio de su incapacidad", que aquellas naciones no sean más "que unos agregados de gentes, á quienes divide y une entre sí la unifomidad ó

\footnotetext{
${ }^{48}$ Ibídem, $\mathrm{x}$

${ }^{49}$ Ibídem, 122.

${ }^{50}$ Ibídem.

${ }^{51}$ Ibídem, 123.

${ }^{52}$ Ibídem, 132.

${ }^{53}$ Ibídem.
} 
diversidad de los lenguajes" ${ }^{, 54}$. Ante la ausencia de leyes que miren a la mutua conservación y aumento, "solo subsiste un tácito decreto, en virtud del qual están prontos á tomar las armas para defenderse ú ofender á otros" ${ }^{\text {"5 }}$.

En relación al "gobierno doméstico" encontramos otro "desbarato y vehetría peor", que puede verse en las costumbres de los jefes sobresalientes: "suelen tener diez o doce mujeres, y a veces más". A esto habría que sumarle el intercambio o préstamos de mujeres y, otras costumbres relacionadas con las formas de "criar" a sus hijos.

Así, su condición es un "digno castigo de su bárbaro estilo", el hecho de que no haya gobierno, orden y enseñanza se debe a que los gentiles "no saben, ni tienen que enseñarle" a sus hijos: "crianse aquellos chicos del mismo modo con que se criáron sus padres; esto es, al modo que se crian saltando y brincando los cabritillos en las manadas de cabras" ${ }^{~} 56$. La retórica de Gumilla traza una analogía entre el salvaje y las bestias, es decir, que utiliza constantemente referencias zoológicas para explicar de manera apropiada cómo se comportan los salvajes. Un ejemplo interesante de este tropo aparece cuando narra el genio de la nación Caberre, copiosa en pueblos y gentío, que no sólo es bárbara, sino también brutal, pues su "vianda ordinaria es carne humana de los enemigos, que buscan y persiguen, no tanto para avivar la guerra, cuanto para apagar su hambre"; o cuando refiere la forma de vida nómada y belicosa de los Guayvas y Chiricoas, que se distinguen muy poco de la vida que llevan las "fieras silvestres".

\section{Genealogía de los nativos americanos}

Uno de los elementos transversales que van a ocupar la obra de Gumilla se refleja en su prólogo:

Así es, y asentado el pié sobre esta firme basa, notemos, que aquella novedad de hombres Americanos, que por extraña se admira, y por irregular no se cree, fué antigua y peynó muchas canas en nuestro Mundo antiguo $^{57}$.

De ese fragmento emerge un principio fundamental: el nativo americano no es del todo novedoso en tanto que criatura de Dios y tiene una genealogía que le otorga un lugar específico en el orden cristiano que requiere y merece ser trazada y (d)escrita con claridad. De allí que, como hemos dicho, en consonancia con el

\footnotetext{
${ }^{54}$ Ibídem, 133.

${ }^{55}$ Ibídem, 134.

${ }^{56}$ Ibídem, 135.

${ }^{57}$ Ibídem, x.
} 
sentido ilustrado-católico de la historia que sustenta El Orinoco ilustrado, uno de los aspectos centrales que van a preocupar a Gumilla será el (d)escribir la historia de los "gentiles sin historia". Esta labor es imperiosa "ya que ellos no saben de su origen", como relata a propósito de los soberbios Caribes ${ }^{58}$, y se hace necesario corregir las narraciones desatinadas de otras naciones, como los Otomacos -que encarnan "la quinta esencia de la misma barbaridad"-, y consideran como sus antepasados a peñascos horrendos ${ }^{59}$.

Del argumento de Gumilla se desprende que la historia verdadera es aquella que es escrita por alguien con la ilustración para hacerlo y que le confiere autoridad. Desde su locus de enunciación, Gumilla cuenta con los pergaminos y el capital simbólico para hacerlo. En efecto, para él esas versiones distorsionadas y erráticas del origen de aquellas naciones parten de la imposibilidad que tienen para pensar y recibir noticias de la existencia de comarcas más lejanas, por lo que no les queda más remedio que recurrir "a las piedras, ríos, árboles, etc., como a fundadores de sus linajes" ${ }^{\prime \prime 0}$. Entonces, ¿cuál es el origen de aquellas naciones?:

Y así yo en su nombre apuntaré aquí lo mismo que largamente medité entre ellos, al ver su modo, su estilo y su desdicha, digna de toda compasion. Digo lo primero, que los Indios son hijos de Chám, segundo hijo de Noé, y que descienden de él al modo que nosotros descendemos de Japhet, por medio de Tubal, Fundador ó Poblador de España, que fué su hijo, y nieto de Noé, y vino á España año 131 después del Diluvio Universal (1788 de la Creacion del Mundo). A este modo á Chám y á sus hijos le cupo la Arabia, el Egypto y el resto de la Africa; y algunos de sus nietos ó viznietos, arrebatados sus Barcos de la furia de los vientos, como en su lugar diré, ó de otro modo, desde Cabo Verde pasáron al Cabo mas abanzado de toda la América Meridional, que está en el Brasíl, y se llama Fernambuco. Pruebo esta conclusion con el infeliz y mísero porte de los Indios Americanos, los quales llevan tácita y pacíficamente el vasallage que deben, y es razon den á nuestros Católicos Monarcas ${ }^{61}$.

Y al tratar de explicar por qué los gentiles sirven con más gusto y mejor aire a un negro esclavo que a un español, continúa más adelante:

¿Qué misterio es éste? pues lo dicho no es observacion especulativa, es muy práctica; y no es reparo solamente mio, es reflexîon hecha ya por otros muchos: ¿y quál será la raíz de un tan raro modo de proceder de los Indios?

\footnotetext{
${ }^{58}$ Ibídem, 111.

${ }^{59}$ Ibídem, 112.

${ }^{60}$ Ibídem.

${ }^{61}$ Ibídem, 115.
} 
respondo, que proceden así, para que se verifique al pié de la letra la maldicion, que quando Noé despertó de su sueño, echó á su hijo Chám, diciéndole: Que habia de ser siervo y criado de los esclavos de sus hermanos. No dixo siervo ó criado de sus hermanos, sino siervo de los esclavos de sus hermanos: y estos son puntualmente los Indios, no por fuerza, sino de su propia inclinacion, verificando la maldicion que Noé echó á Chám ${ }^{62}$.

La aseveración de atribuirle a los descendientes de Cam el origen de estas naciones americanas, encuentra un refuerzo en sus valores invertidos como la desnudez o la tendencia a embriagarse. Adicionalmente, equipara con que los "Indios judaizan",63 a ciertas practicas locales como la circuncisión, la poligamia o llamar hermano(a) a parientes de segundo y tercer grado, ya que una vez llegaran los descendientes de Cam a estas latitudes, lo propio harían: "Algún número de Hebréos, despues de la dispersion de aquel ingrato Pueblo, de los quales redundáron á los primeros pobladores las ceremonias, que iré apuntando de paso" ${ }^{, 64}$.

El trazo de la diversidad lingüística de estas naciones será un elemento que le permitirá corroborar este último planteamiento. Veamos:

Y así miéntras la erudicion y el tiempo trabajáren sobre esta dificultad, tomemos un medio término racional y factible; y digamos, pues tenemos á nuestro favor las sagradas Letras, que desde la Torre de Babél, de donde saliéron los Operarios tan bien aviados de nuevas lenguas, que ninguno entendia á otro, cada qual, con sus hijos y muger, tomó diverso rumbo: super faciem cunctarum Regionum; y que quantas familias llegáron á las Américas, (sea por donde se fuere) otras tantas fuéron las lenguas que en aquellos remotos Paises se entabláron: resultando con el tiempo, del aumento de estas familias nuevas divisiones hácia nuevos territorios; y de aquí nuevas divisiones de lenguas subalternas, como ya apunté: opinion, que siguen graves Autores: y así es muy creible, que como en la dispersion de Babél del año 1800. de la creacion del Mundo, pasáron muchas familias á las Américas; así en la dispersion de las diez Tribus de Israél del año 3283. de la creacion del Mundo, pasasen muchas mas familias Hebréas, de quienes los antiguos moradores de aquel Nuevo Mundo tomasen las ceremonias Judáicas, que se han notado entre los Indios, admitidas á los 1483. años despues de su primera poblacion: al modo que tantas Naciones y Pueblos, que siguen hoy la detestable Secta de Mahoma, observan gran

\footnotetext{
${ }^{62}$ Ibídem, 116.

${ }^{63}$ Ibídem, 120.

${ }^{64}$ Ibídem, 118.
} 
número de ceremonias judáicas; sin que por eso podamos decir, que estas gentes descienden de los judíos ${ }^{65}$.

La pregunta indiscutible que surge de este planteamiento es: ¿cómo llegaron al Nuevo Mundo los descendientes de Cam y los hebreos? Aunque en una de los fragmentos arriba citados sugiere la ruta Cabo Verde-Fernambuco como puente de comunicación, Gumilla desarrolla un argumento contundente en el capítulo titulado De las primeras gentes que pasaron a América y el modo, en el cual sostiene que la capacidad de erigir embarcaciones marítimas es un legado de los descendientes de Noé que debieron poblar aquellas latitudes, y una vez en el mar pudieron ser "arrebatadas" por las corrientes y llevados por el azar a estas costas. Se sustenta en hechos recientes para su época, como el de un barco zarpado en Tenerife de Canarias con destino final otra isla de las Canarias, que por azares del destino llegó a doce leguas de las bocas del Orinoco, en San José de Oruña o también en el relatos más antiguos como el de bretones, canarios, fenices o vizcaínos que llegaron en diversos tiempos a diferentes lugares de la costa ubicada al levante de América.

Ahora bien, otro interrogante de fondo emerge en la argumentación de Gumilla: si los primeros pobladores de América llegaron a sus costas en barco por los avatares de las corrientes marinas, entonces ¿qué sucede con las especies animales que habitan América cuyo rastro no queda en la memoria del Viejo Mundo? Para Gumilla la respuesta -que no puede ser definitiva ya que merece "que algun noble ingenio la discurra" ${ }^{, 66}$-, se resuelve argumentando que es probable que hayan migrado en los mismos barcos que llevaron a los primeros pobladores del continente. En efecto, luego de descartar hipótesis sobre el poblamiento vía terrestre a través de eventuales enlaces como la Atlántida, el Estrecho de Davis o de Anian, Gumilla argumenta que "por el ministerio de los mismos Angeles fuéron llevados, despues del diluvio, á diversas partes del mundo, en donde habian sido criadas" ${ }^{67}$. En conjunto, la preocupación por el verdadero origen de los gentiles americanos lleva a Gumilla a formular la hipótesis de poblamiento del continente y a trazar una clara genealogía de estos pobladores con la tradición judeo-cristiana que les transfiere la condición de ser criaturas de Dios, y por consiguiente, susceptibles y aptos para recibir su gracia a través de la cristianización.

\section{El cultivo de la mies: efectos pragmáticos de El Orinoco ilustrado}

\footnotetext{
${ }^{65}$ Ibídem, 2: 41-42.

${ }^{66}$ Ibídem, 2: 50.

${ }^{67}$ Ibídem, 2: 51.
} 
La obra es concebida por su autor como un documento que dará noticias que "prevengan los ánimos de los operarios" de la Compañía de Jesús y provean algunas luces para el ejercicio de aquellos "que Dios Nuestro Señor llamare al cultivo espiritual de aquella mies"68. ¿Cómo evangelizar de manera eficaz a gentiles incógnitos de disímil carácter y costumbres? Unas peticiones de principio: primero, Gumilla recomendará vivamente promover el buen trato de los nativos para acercarlos a las misiones a través de "los beneficios, suavidad y muestras prácticas de amor" ${ }^{\prime 69}$, tal y como sucedió con los temibles caberres -que aún sometían a los feroces caribes-, que fueron a las misiones jesuitas "y se volviéron contentos, porque fuéron bien recibidos y agasajados" ${ }^{\text {" }}$. Segundo, solo con tiempo, paciencia, perseverancia y confianza en Dios se podrá cultivar en la fe católica a los más rebeldes. Estas condiciones son el precio a pagar por el misionero, pero constituyen, simultáneamente, sacrificios que glorifican al Señor. Así, al demostrar el esfuerzo que implica dejar atrás su comarca y sus parientes "para salvar aquellas almas destituidas de todo cultivo espiritual" ${ }^{11}$, el operario puede invocar la caridad de su obra para lograr la compasión de los gentiles y potenciar el logro de su misión:

[...] conviene que el Misionero explique muy de espacio el viage que ha hecho desde Europa hasta sus tierras, à fin de enseñarles el camino del Cielo; porque como ellos tienen un amor tan bestial à sus Paises, que casi se puede llamar querencia, que es la que las bestias tienen á los exidos de su pasto; les causa mucha armonía, que el Misionero, solo por cuidarlos, y enseñarles, haya dexado su Patria y parientes, y haya caminado tanto. Digo esto, porque en circunstancias, en que algunos Pueblos recien agregados de los bosques, ya por instigacion de los ancianos, ya por la del Demonio, estaban mal contentos, y deseosos de volverse à su Egipto, fui repetidas veces à oir à escondidas sus conversaciones, $\mathrm{y}$ en muchas de ellas oi esta réplica: “¿Cómo nosotros podemos dexar al Padre que por nuestro bien ha dexado à sus parientes? ¿Y qué mucho nos apartemos pocas millas de nuestra tierra, quando el Padre por nosotros se ha alexado tanto de la

\footnotetext{
${ }^{68}$ Según el Diccionario de la Real Academia Española de la Lengua, la mies alude a: 1. Cereal de cuya semilla se hace el pan; 2 . Tiempo de la siega y cosecha de granos; 3. Muchedumbre de gentes convertidas a la fe cristiana, o prontas a su conversión; 4. Conjuntos de sembrados de un valle; 5 . Sembrados. La tercera definición aparece como la más cercana al sentido figurado que Gumilla utiliza para hacer referencia a los gentiles y la labor misional. Real Academia Española, Diccionario de la Lengua Española, 22 ed. (Madrid: Real Academia Española de la Lengua, 2001), 1019. Gumilla, Historia Natural, iv.

${ }^{69}$ Ibídem, 318.

${ }^{70}$ Ibídem, 251.

${ }^{71}$ Ibídem, 303.
} 
suya?" Estas razones, tengo experiencia, que les hacen gravísima fuerza, y que producen muy buenos efectos ${ }^{72}$.

Sin embargo, los misioneros debían hacer frente a la inconstancia, nomadismo y terquedad de algunas de estas naciones, porque a pesar de los esfuerzos para el cultivo de sus almas podían recibir como pago un campo "estéril, árido é ingrato; [que] en lugar del fruto correspondiente, no ha producido sino espinas y abrojos" ${ }^{\text {"73, }}$, como sucedió con los andantes guayvas y chiricoas de las riberas del río Meta. Para solventar estos posibles contratiempos, Gumilla recomienda que los nuevos operarios: "Se informen muy despacio del modo y de las reglas de prudencia, que la experiencia ha enseñado á los ya versados, para proceder con acierto en tales y tales Naciones" ${ }^{\text {, }}$.

Por lo tanto, pasando a un nivel pragmático y apelando a su experiencia, Gumilla propone que el misionero debe "instruir bien dos o más indios los neófitos" competentes en la lengua de la nueva nación a la que se le llevará la buena nueva. Entre otras labores, estos neófitos deben dar noticia de tal nación indicando en primera instancia si se trata de amigos o no, si son belicosos o pacíficos, etc. El operario no debe acudir directamente a la nueva nación, sino que adiestrará a los neófitos como embajadores enviándolos con regalos para los líderes. El tacto de esta labor será crucial para el éxito de la incorporación del operario a la nueva nación, "porque los Gentiles les están preguntando de noche y de dia, y las respuestas de los Neófitos les van ablandando los corazones, y abriéndoles los ojos" ${ }^{, 75}$. Por otra parte, Gumilla no se detiene en prevenir a los misioneros de eventuales atenciones de parte de los gentiles, excepto una en particular: cuando se le ofrece "una mujer que le asista y sirva" frente a lo cual el operario tendrá la oportunidad de demostrar su grandeza y ser concebido por los indios "como cosa muy superior a ellos", renunciando a la mujer ofrecida, porque "todo su amor tiene colocado arriba en el cielo; y que de ellos no quiere cosa alguna en este mundo, sino mirarlos como a hijos para cuidar de su bien, etc. ${ }^{~}{ }^{\text {. }}$.

Entonces, acogiendo tales recomendaciones, se podrá alcanzar "el fin principal", que "es ganar para Dios aquellas almas", es decir, cultivar la mies que se cosechará en beneficio del Señor y acoger con valor la paciencia que requiere el ejercicio misional, porque:

[...] llegará su propio tiempo y tendréis tan abundante cosecha, que apénas tendréis manos, ni fuerza para recogerla toda, y os veréis obligados á clamar

\footnotetext{
72 Ibídem, 2: 276-277.

${ }^{73}$ Ibídem, 255-256.

${ }^{74}$ Ibídem, 2: 291.

${ }^{75}$ Ibídem, 312.

${ }^{76}$ Ibídem, 314-315.
} 
á los Superiores, que envien nuevos Operarios, porque la mies es mucha, se cae de puro madura, y se pierde porque los Operarios son pocos; de modo, que al paso que tardó el terreno en fomentar la semilla que ocultaba, á ese paso es despues la abundancia del fruto en las Misiones de Gentiles, y no fruto transeúnte, sino fixo y permanente ${ }^{77}$.

Gumilla propondrá algunas "reflexiones que animan y fortalecen el ánimo del Misionero de Indios", donde invocará la teleología de la labor misional: un servicio que glorifica al Señor, salva a quien la ejerce y sobre quienes se ejerce, recibiendo como recompensa la bienaventuranza eterna. Así, El Orinoco ilustrado tendrá la pretensión de constituirse en una "carta de navegar en el peligroso mar de indios gentiles", tal y como Gumilla titula el epígrafe de la segunda edición del libro.

Otro elemento pragmático que atraviesa la obra de Gumilla está relacionado con la justificación del proyecto civilizatorio-cristiano en tierras americanas. En el siglo XVIII, las discusiones sobre el alarmante decrecimiento demográfico de las poblaciones americanas resultaron centrales: "en un siglo poblacionista, la palabra [despoblación] es una condena" "78, por lo que los impulsores de los dispositivos coloniales en América, entre ellos los misioneros, no podían admitir de ninguna manera la responsabilidad del imperio español en la catástrofe demográfica de las naciones americanas.

Gumilla dedicará los capítulos finales a su obra para terciar en favor del imperio como respuesta a aquellos que le endilgan la causa del decrecimiento demográfico de los nativos, sustentados en "la mortandad de indios", el "trabajo personal impuesto", "las viruelas y contagios" y "los tributos y cargas impuestas". En este sentido, dirá que las causas de la escasez poblacional obedecen a factores internos de aquellas naciones y no a la obra de los españoles, quienes, por lo demás, no pueden ser responsables en la medida que son hombres racionales. De allí que, entre otras $\operatorname{cosas}^{79}$, destaque tres causas principales: primero, la guerra entre naciones, que constituye una "causa extrínseca, y digámoslo así, forastera, de la ruina de casi todas las naciones de este gran río" ${ }^{" 80}$; segundo, las guerras internas o "mutua carnicería" que es "el frecuente y cruel uso de darse veneno los de la misma Nacion unos á otros, por causas muy leves" ${ }^{\prime \prime 1} \mathrm{y}$, tercero, el infanticidio que

\footnotetext{
${ }^{77}$ Ibídem, 305.

${ }_{78}^{78}$ Duchet, Antropología e historia, 181.

${ }^{79}$ De manera muy particular, Gumilla expondrá que esas otras causas están directamente relacionadas con usos "contra su salud", entre las cuales enumera: "la ninguna piedad que tienen con sus enfermos; otra, la voracidad con que comen quando hallan ocasion: tercera, la desnudez y desabrigo; cuarta, el arrojarse al rio á lavarse, aunque estén sudando". Gumilla, Historia Natural, 2: 64.

${ }^{80}$ Ibídem, 2: 58.

${ }^{81}$ Ibídem, 2: 58.
} 
constituye una "depravada intención [que] nace en su gentilidad"; estas dos últimas constituyen -según Gumilla- causas "más sensibles, por ser domésticas y no menos inhumanas" 82 . A estas causas, el jesuita añadirá dos no menos importantes: la migración voluntaria de muchas naciones "a otra espesura impenetrable" y la esterilidad voluntaria con yerbas naturales. Luego de enumerar las causas intrínsecas de la "aparente" debacle demográfica que se aprecia en algunas naciones, salvará de responsabilidad a los ibéricos sobre el particular:

De modo, que ni las guerras, ni el trabajo personal, ni las pestes, ni los tributos y opresiones, con tal, que no sean de una exôrbitancia nunca vista, pueden ser causa total y suficiente para disminuir tan notablemente las Naciones ${ }^{83}$.

En conjunto, los efectos pragmáticos más relevantes explicitados en El Orinoco ilustrado giran en torno al enaltecimiento de los valores cristianos en el trato a los gentiles; a la proposición de algunas estrategias específicas y recomendaciones útiles para acceder a las nuevas naciones que se iluminarán con la gracia divina; $\mathrm{y}$, finalmente, a la reivindicación del proyecto civilizatorio de la Corona española en las provincias americanas.

\title{
Conclusiones
}

\begin{abstract}
"Aquellos indios bárbaros, desnudos, silvestres, rudos, y á la primera vista despreciables, son unas conchas toscas, que encierran en sí unas margaritas tan preciosas, que el mismo Hijo de Dios se dió á sí mismo en precio, y se entregó á los tormentos para adquirirlas: ¡quánto debo yo apreciarlas!" ${ }^{4}$
\end{abstract}

El Orinoco ilustrado constituye un documento de un alto valor etnográfico para entender el contexto ideológico e intelectual que da forma al libro. Como tal puede ser objeto de una aproximación hermenéutica que enfatice en los aspectos culturales, políticos e ideológicos que lo configuran. En el texto se puede aprehender una retórica colonial constituida por una episteme ilustrada y cristiana que determina la forma de nombrar, elaborar y describir al otro. Ciertamente, está episteme presenta continuidades evidentes con el pensamiento del siglo XVI en lo que respecta a las nociones de historia y naturaleza del salvaje. Si bien los principios constitutivos de esta episteme pueden parecer contradictorios, revelan más bien el locus de enunciación de Gumilla. En efecto, y fundamentado en la superioridad moral del europeo evangelizador, él elaborará una cartografía de la

\footnotetext{
${ }^{82}$ Ibídem, 2: 60.

${ }^{83}$ Ibídem, 2: 313.

${ }^{84}$ Ibídem, 2: 346.
} 
alteridad en las tierras del Orinoco cuya matriz valor-antivalor es la forma de catalogar al otro. Es decir, el salvaje es al mismo tiempo ausencia de civilización y concreción de los valores invertidos del cristianismo. La diferencia colonial en $\mathrm{El}$ Orinoco ilustrado establece una triple distancia: geográfica, temporal y cultural. Desde allí se naturaliza al otro como alguien radicalmente distinto, aunque susceptible, por lo mismo, de ser evangelizado. Así mismo, la retórica colonial se hace más clara cuando se acude al cuerpo, como instancia de cristalización del salvajismo, a la ignorancia y al desgobierno que caracterizan a los gentiles, y cuando se traza la genealogía que explica su origen y situación. A partir de ella, Gumilla ilustra y construye al gentil-salvaje del Orinoco.

Ahora bien, el gentil-salvaje aparece, sin embargo, como una categoría genérica que se matiza a medida que se describen las costumbres y prácticas concretas de cada una las naciones de la región. Esto marca una axiología: unos serán más salvajes o bestiales que otros, pero, sin importar su grado de salvajismo, comparten la condición de ser criaturas de Dios y, por ello mismo, son susceptibles de ser iluminados con su gracia. Cultivar y cosechar las mieses condensa el fin último del proyecto misional al glorificar la obra de Dios y abrir a los salvajes el camino de la civilización y la salvación. De cierta manera, la retórica de Gumilla responde a los imperativos de la episteme clásica en la cual confluyen lo bueno, lo bello y lo verdadero. Las virtudes aparecen inseparables de lo verdadero y se expresan en la belleza de sus actos. Gumilla "observó de primera mano" las conductas salvajes de los gentiles, cuya fealdad y salvajismo son expresiones de su ignorancia, equivocación e inmoralidad, mientras que el misionero encarna la belleza de la virtuosidad. Así, la equivalencia entre lo bello, lo bueno y lo verdadero constituye el patrón de observación del misionero jesuita.

Después de marcar retóricamente la diferencia de la alteridad, es decir, su naturaleza y funcionamiento, Gumilla hará participes a los gentiles de la genealogía cristiana dándoles un lugar bastante peculiar en el orden del mundo de Dios, quizás como hijos negados o vástagos que renunciaron a él. Con la descripción de su salvajismo adquiere sentido la necesidad de la evangelización; simultáneamente, el estudio del Orinoco, de sus lugares y gentes, será una forma de glorificar a Dios, al conocer y dar cuenta de la grandeza de su genio creativo. En conjunto, Gumilla iluminará, es decir, ilustrará al Orinoco y sus pobladores generando un artificio retórico de doble sentido: Europa conocerá sobre la "verdad" de estas naciones a la vez que Gumilla les escribirá su historia y les decretará el camino civilizatorio a través del paradigma cristiano. De tal manera, en el siglo XVIII civilizar equivale a emancipar ${ }^{85}$, por lo cual, aunque suene contradictorio, perder la libertad es el precio a pagar por liberarse del mundo pagano.

${ }^{85}$ Duchet, Antropología e historia, 195. 


\section{Bibliografía}

Arboleda, José Rafael. "El padre Gumilla S. J. y su obra". En El Orinoco ilustrado. Historia Natural, Civil y Geográfica de este gran río. Bogotá: ABC, 1955.

Barona, Guido. "Las tecnologías de dominación colonial: el derecho, los pueblos de indios y resguardos". Revista de Antropología y Arqueología (Bogotá), 10, núm. 2, (1998): 93-140.

" "Memoria y olvido: pasión, muerte y renovación de la colonización del imaginario". En Memorias hegemónicas, memorias disidentes. El pasado como política de la historia, eds. Marta Zambrano y Cristóbal Gnecco, 121-150. Bogotá: Ministerio de Cultura; Instituto Colombiano de Antropología e Historia; Universidad del Cauca, 2000.

Bartra, Roger. El salvaje en el espejo. Barcelona: Destino, 1996.

Beerman, Eric. "Retrato biográfico de Francisco Requena (1743-1824)". Boletín de Historia y Antigüedades (Bogotá), 85, núm. 801 (1998): 495-518.

Borja G., Jaime H. Los indios medievales de Fray Pedro de Aguado. Construcción del idólatra y escritura de la historia en una crónica del siglo XVI. Bogotá: Pontifica Universidad Javeriana; Instituto Colombiano de Antropología e Historia; Instituto Pensar; Universidad Iberoamericana de México, 2002.

Chaumeil, Jean-Pierre. "De Loreto à Tabatinga. D'une frontière l'autre: antagonisme sur l'Amazone au XIX $X^{e}$ siècle et aprè". L'Homme (Paris) 32, núm. 122-124, (1992): 355-375.

Alcedo y Herrera, Dionisio de. "Dictamen de D. Dionisio de Alcedo y Herrera, Gobernador y Capitán General que fue de la Provincia de Quito, y Presidente de la Real Audiencia de dicha ciudad, en orden al contenido de esta historia". En El Orinoco ilustrado. Historia Natural, Civil y Geográfica de este gran río, José Gumilla. 1741; Bogotá: ABC, 1955.

Goyeneche, Antonio de. "Aprobación del R. P. Maestro Antonio de Goyeneche, de la Compañía de Jesús". En El Orinoco ilustrado. Historia Natural, Civil y Geográfica de este gran río, José Gumilla. 1741; Bogotá: ABC, 1955. 
Rey Fajardo, José del. Misiones jesuíticas en la Orinoquia. Caracas: Universidad Católica Andrés Bello, 1977.

"La presencia científica de la Universidad Javeriana en la Orinoquia". Boletín de Historia y Antigüedades (Bogotá), 79, núm. 179 (1992): 925-952.

"El mundo intelectual y simbólico del misionero orinoquense". En Un reino en la frontera. Las misiones jesuitas en la América colonial, coords. Sandra Negro y Manuel M. Marzal. Lima: Pontificia Universidad Católica del Perú; Abya-Yala, 2000.

El aporte de la Javeriana colonial a la cartografia orinoquense. Bogotá: Pontificia Universidad Javeriana, 2003.

Duchet, Michèle. Antropología e historia en el siglo de las Luces. México: Siglo XXI, 1975.

Fanon, Frantz. Los condenados de la tierra. 1961; reimpresión, Santafé de Bogotá: Fondo de Cultura Económica, 1999.

Foucault, Michel. Las palabras y las cosas. Una arqueología de las ciencias humanas. 1966; México: Siglo XXI, 1998.

Gómez, Augusto. Indios, colonos y conflictos. Una historia regional de los Llanos Orientales. 1870-1970. Bogotá: Pontificia Universidad Javeriana; Instituto Colombiano de Antropología; Siglo XXI, 1991.

Gumilla, José. Historia Natural, Civil y Geográfica de las Naciones situadas en las riveras del Río Orinoco, 2 T. 1741; Barcelona: Carlos Gibert y Tutó, 1791.

El Orinoco ilustrado. Historia Natural, Civil y Geográfica de este gran río. 1741; Bogotá: ABC, 1955.

El Orinoco ilustrado. 1741; Bogotá: Imagen, 1994.

Langebaek, Carl y otros. Por los caminos del piedemonte. Una historia de las comunicaciones entre los Andes orientales y los Llanos. Siglos XVI a XIX, Estudios Antropológicos, núm. 2. Santafé de Bogotá: Universidad de los Andes, 2000.

Mignolo, Walter. Local histories/global designs. Coloniality, subaltern knowledge and border thinking. Princeton: Princeton University Press, 2000. 
Pacheco, Juan Manuel. Los jesuitas en Colombia. T. 3. 1696-1767; Bogotá: Universidad Javeriana, 1989.

Parker, Eugene. "Caboclization: The transformation of the amerindian in Amazonia 1615-1800". Studies in Third World Societies (Williamsburg, Estados Unidos), 32 (1985): 1-49.

Pels, Peter. "The anthropology of colonialism: Culture, history, and the Emergence of Western Governmentality". Annual Review of Anthropology (Palo Alto, Estados Unidos), 26 (1997): 163-183.

Ramírez, María Clemencia. "Los sibundoyes, grupos de piedemonte estructuradores de la relación de intercambio Andes-selva durante el siglo XVII". En Pasado y presente del Amazonas: su historia económica y social, comps. Roberto Pineda y Beatriz Alzate, 19-30. Santafé de Bogotá: Presidencia de la República, 1993.

Rausch, Jane. Una frontera de la sabana tropical. Los Llanos de Colombia 15311831. Santafé de Bogotá: Banco de la República, 1994.

Real Academia Española. Diccionario de la Lengua Española. 22 ed. Madrid: Real Academia Española de la Lengua, 2001.

Reeve, Mary-Elizabeth. "Regional interaction in the western Amazon: The early colonial encounter and Jesuit years: 1538 - 1767". Ethnohistory (Durham, Estados Unidos) 41, núm. 1 (1994): 106-138.

Restrepo, Daniel. La compañía de Jesús en Colombia: compendio historial y galería de ilustres varones. Bogotá: Corazón de Jesús, 1940.

Salcedo, Jorge Enrique. "Las misiones jesuitas en Colombia, las regiones del Casanare y el Meta durante el siglo XVII y XVIII". En Un reino en la frontera. Las misiones jesuitas en la América colonial, coords. Sandra Negro y Manuel M. Marzal. Lima. Pontificia Universidad Católica del Perú; Abya-Yala, 2000.

Sweet, David. "Misioneros jesuitas e indios 'recalcitrantes' en la Amazonia Colonial". En De palabra y obra en el Nuevo Mundo, eds. Miguel LeónPortilla y otros, 265-292. Madrid: Siglo XXI, 1992.

Useche, Mariano. "Colonización española e indígenas en el alto Orinoco, Casiquiare y río Negro". En Etnohistoria e Historia de las Américas, 
comp. Elizabeth Reichel, 225-242. Bogotá: Universidad de los Andes, 1988.

Fecha de recepción: 3 de abril de 2006.

Fecha de aprobación: 14 de junio de 2006. 